\title{
Long-time resistivity monitoring of a freshwater/saltwater transition zone using the vertical electrode system SAMOS
}

\author{
Michael Grinat ${ }^{1}$, Dieter Epping ${ }^{1}$ and Robert Meyer ${ }^{1}$ \\ ${ }^{1}$ Leibniz Institute for Applied Geophysics, Hannover, Germany
}

\begin{abstract}
In September 2009 two newly developed vertical electrode systems were installed in boreholes in the water catchment areas Waterdelle and Ostland at the North Sea island Borkum to monitor possible changes of the transition zone between the freshwater lens and the underlying saltwater. The vertical electrode systems, which were both installed between $44 \mathrm{~m}$ and $65 \mathrm{~m}$ below ground level, are used for geoelectrical multi-electrode measurements carried out automatically several times per day; the measurements are still ongoing. The whole system consisting of a vertical electrode system in a borehole and the measuring unit at ground level is called SAMOS (Saltwater Monitoring System).
\end{abstract}

At both locations the data show a clear resistivity decrease that indicates the transition zone between freshwater and saltwater. The depth of the transition zone as well as the kind of resistivity decrease is very stable since 2010 .

Temporal changes are visible if single depths are considered. In 2015 Miriam Ibenthal used a vertical 2D density-dependent groundwater flow model to explain the long-term resistivity measurements and showed that the temporal changes at CLIWAT 2 (Ostland) could be explained by variations of the groundwater level, changing groundwater recharge rates and changing pumping rates of the nearby located drinking water supply wells.

\section{INTRODUCTION}

At the North Sea island Borkum the necessary freshwater is completely taken from the freshwater lens. The water is extracted in the two water catchment areas Waterdelle and Ostland. Within these water catchment areas up-coning of saltwater caused by high pumping rates in the wells is a permanent threat. This up-coning should lead to changes of the depth and shape of the transition zone between the freshwater lens and the underlying saltwater; therefore a system that monitors the transition zone acts as an early-warning system.

In September 2009 newly developed vertical electrode systems were installed in boreholes in each of the two water catchment areas Waterdelle and Ostland to monitor possible changes of the transition zone between the freshwater lens and the underlying saltwater. The transition zone is located in depths between $44 \mathrm{~m}$ and $65 \mathrm{~m}$ below ground level. The installation as well as the first measurements were carried out in the framework of the EU Interreg project Climate \& Water (see http://cliwat.eu/, Sulzbacher et al. 2012, Wiederhold et al. 2013). Therefore the boreholes were called CLIWAT 1 (Waterdelle) and CLIWAT 2 (Ostland).

Each of the two vertical electrode systems is about $20 \mathrm{~m}$ long and includes 78 stainless steel ring electrodes. The spacing between adjacent electrodes is $0.25 \mathrm{~m}$. The electrodes are mounted on an isolating PVC rigid pipe. After the installation of the vertical electrode systems the boreholes were refilled with material similar to the sediments that were found in 
the correspondent depths. Moreover, two water gauges with filters in different depths were installed above each of the vertical electrode systems to monitor the groundwater level.

The measuring system is installed at ground level. The geoelectrical measurements are carried out automatically several times per day using a modification of the commercial resistivity meter 4point light 10W (see www.l-gm.de). The power is supplied by batteries recharged by solar panels. Since December 2009 the data are regularly transmitted to Hannover by telemetry. The automated measurements are still ongoing. The whole system consisting of the vertical electrodes in a borehole and the measuring unit at ground level is called SAMOS (Saltwater Monitoring System).

Recently, similar systems were also used by Ogilvy et al. (2009) and Poulsen et al. (2010) for monitoring coastal aquifers.

\section{RESULTS}

The geoelectrical multi-electrode measurements are carried out automatically using the Wenner-alpha array (electrode spacings between $0.25 \mathrm{~m}$ and $6.25 \mathrm{~m}$ ). Each multi-electrode measurement includes 975 different four-point arrays.

In the beginning the measurements were strongly influenced by moisture effects and showed a lot of outliers, but the use of newly developed active electrode switchboxes increased the quality of the data very much. In the last years a maintenance of the system at ground level was necessary once to twice a year only.

At both locations CLIWAT 1 and CLIWAT 2 the data show a clear decrease of the apparent resistivity from about $80-90 \Omega \mathrm{m}$ in depths around $45 \mathrm{~m}$ to about $1-2 \Omega \mathrm{m}$ around $65 \mathrm{~m}$ depth (spacing $\mathrm{a}=0.25 \mathrm{~m}$ ). This decrease indicates the transition zone between freshwater and saltwater. In CLIWAT 1 only sand is found in the transition zone, but in CLIWAT 2 several layers of clay and silt were encountered within the sandy sediments in the depth of the transition zone. The different layers are clearly visible in the resistivity measurements: In the transition from resistivities of about $80 \Omega \mathrm{m}$ around $45 \mathrm{~m}$ depth to $2 \Omega \mathrm{m}$ around $65 \mathrm{~m}$ depth the sand layers show slightly higher resistivities than the clay layers (fig. 1).

Since 2010 the depth of the transition zone as well as the kind of decrease of the apparent resistivity is very stable (fig. 1). Only within the first year large changes occurred, but these were caused by the readjustment of the local conditions (disturbed by drilling) to the undisturbed situation.

Temporal changes are only visible if single depths are considered. They are especially large in CLIWAT 2 (Ostland) in depths around $55 \mathrm{~m}$ (fig. 2). Here a sand layer confined by clay layers is found. In 2015 Miriam Ibenthal used a vertical 2D density-dependent groundwater flow model to explain the long-term resistivity measurements and showed within her master thesis at the University of Göttingen that these temporal changes could be explained by variations of the groundwater level, changing groundwater recharge rates and changing pumping rates of the nearby located drinking water supply wells (Ibenthal 2015). SAMOS will also be used in the projects TOPSOIL and GO-CAM (Wiederhold et al. 2018). 


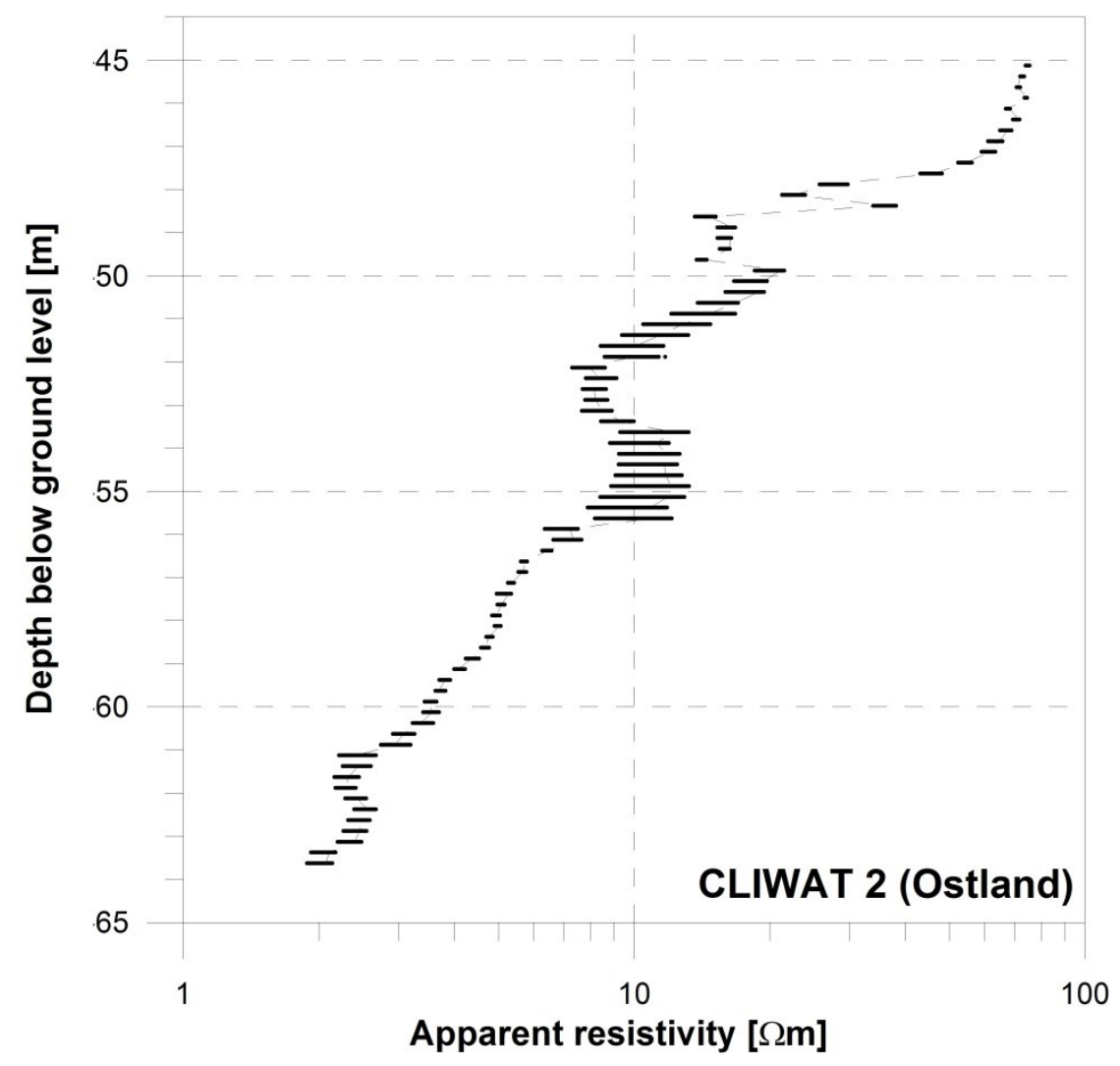

Figure 1. Time lapse of apparent resistivity in CLIWAT 2 between 2011 and 2017 (electrode spacing $0.25 \mathrm{~m}$ ).

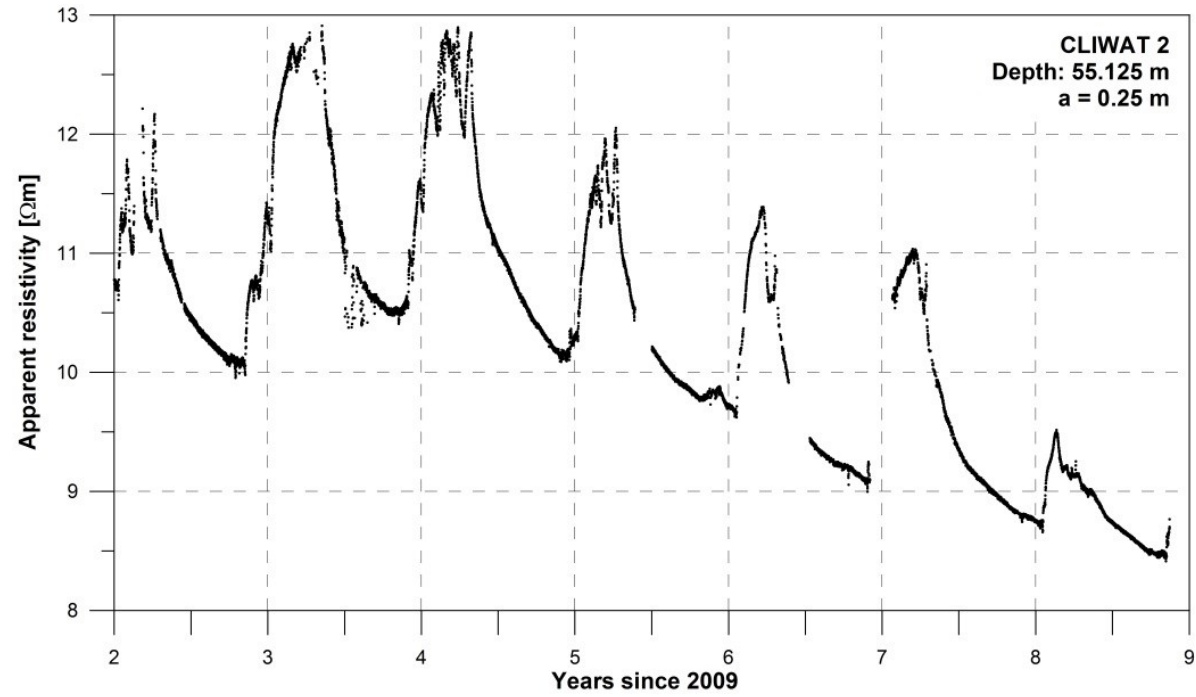

Figure 2. Time lapse of apparent resistivity in CLIWAT 2 in $55.1 \mathrm{~m}$ depth below ground level between 2011 and 2017 (electrode spacing a: $0.25 \mathrm{~m}$ ).

\section{REFERENCES}

Ibenthal, M. 2015. A 2D density-dependent groundwater flow model to explain vertical distribution of electrical conductivity measurements and hydraulic heads of Borkum Island. Master Thesis, Georg August University Göttingen. 
Ogilvy, R. D., P. I. Meldrum, O. Kuras, P. B. Wilkinson, J. E. Chambers, M. Sen, A. PulidoBosch, J. Gisbert, S. Jorreto, I. Frances, and P. Tsourlos. 2009. Automated monitoring of coastal aquifers with electrical resistivity tomography. Near Surface Geophysics 7: 367-375.

Poulsen, S. E., K. R. Rasmussen, N. B. Christensen, and S. Christensen. 2010. Evaluating the salinity distribution of a shallow coastal aquifer by vertical multielectrode profiling (Denmark). Hydrogeology Journal 18: 161-171.

Sulzbacher, H., H. Wiederhold, B. Siemon, M. Grinat, J. Igel, T. Burschil, T. Günther, and K. Hinsby. 2012. Numerical modelling of climate change impacts on freshwater lenses on the North Sea Island of Borkum using hydrological and geophysical methods. Hydrol. Earth Syst. Sci. 16: 3621-3643; doi: 10.5194/hess-16-3621-2012.

Wiederhold, H., H. Sulzbacher, M. Grinat, T. Günther, J. Igel, T. Burschil, and B. Siemon. 2013. Hydrogeophysical characterization of freshwater/saltwater systems - case study: Borkum Island, Germany. First Break 31: 109-117.

Wiederhold, H., W. Scheer, R. Kirsch, M. A. Rahman, and M. Ronczka. 2018. Saltwater intrusion under climate change in North-Western Germany - mapping, modelling and management approaches in the projects TOPSOIL and go-CAM. 25th Saltwater Intrusion Meeting, Gdansk, Poland, this volume.

Contact Information: Michael Grinat, Leibniz Institute for Applied Geophysics, Stilleweg 2, 30655 Hannover, Germany, Email: michael.grinat@liag-hannover.de 